\title{
Ters Basamaklı Eşikler Kullanılarak Tasarlanan Basamaklı Savakların Enerji Sönümleme Oranlarının Sayısal Olarak Incelenmesi
}

\author{
Erdinç İkincioğulları ${ }^{*}$ \\ 1* Bingöl Üniversitesi, Mühendislik Mimarlık Fakültesi, İnşaat Mühendisliği Bölümü, Bingöl, Türkiye, (ORCID: 0000-0003-2518-980X), \\ erdincikinciogullari@gmail.com
}

(Illk Geliş Tarihi 12 Ocak 2021 ve Kabul Tarihi 20 Mart 2021)

(DOI: 10.31590/ejosat.859116)

ATIF/REFERENCE: İkincioğulları, E. (2021). Ters Basamaklı Eşikler Kullanılarak Tasarlanan Basamaklı Savakların Enerji Sönümleme Oranlarının Sayısal Olarak İncelenmesi. Avrupa Bilim ve Teknoloji Dergisi, (23), 189-196.

$\ddot{O} \mathbf{z}$

Basamaklı savaklar, şüt kanalı üzerindeki akım enerjisini sönümleyebilmek amacıyla tasarlanan ve yüzyıllardır kullanılan bir savak çeşididir. Bu savakların geliştirilebilmesi amacıyla basamak geometrisi üzerine birçok çalışma yapılmış ve yapılmaya devam etmektedir. Bu çalışma kapsamında, basamak uçlarına eklenen ters basamak geometrisindeki eşiklerin enerji sönümleme oranına etkisi Flow3 ${ }^{\circledR}$ yazılımı ile incelenmiştir. Üç farklı model ve altı farklı debi kullanılarak sürdürülen çalışmada toplam 18 adet analiz yürütülmüştür. Elde edilen sonuçlara göre, her bir basamak ucuna eklenen ters basamaklı eşiklerin, sıçramalı akım şartlarında, klasik basamaklı savaklardan \%18'e kadar daha fazla enerji sönümleyebildiği, bu değerin nap akımı rejimine geçildikçe azaldığı gözlenmiştir.

\section{Numerical Analysis of Energy Dissipation of Stepped Weirs Designed Using Reverse Stepped Thresholds}

\begin{abstract}
Stepped weirs are a type of weir that has been designed for centuries to dissipate the flow energy on the chute channels. Many studies have been done on step geometry and are still being done to improve these weirs. In this study, the energy dissipation of the weir using reverse step thresholds has been examined with the Flow $3 \mathrm{D}^{\circledR}$ software. A total of 18 analyzes were conducted using three models and six discharges. According to the results, the stepped weir designed using the reverse step thresholds could dissipate energy up to $18 \%$ more than the flat stepped weirs in the skimming flow regime. However, this value decreases as it passes towards the nappe flow regime.
\end{abstract}

Keywords: Stepped spillway, Flow3D ${ }^{\circledR}$, Computational fluid dynamics (CFD).

\footnotetext{
* Sorumlu Yazar: erdincikinciogullari@gmail.com
} 


\section{Giriş}

İnsan nüfusu arttıkça enerjiye olan ihtiyacımız da günden güne artmaktadır. Artan enerji ihtiyacını dengeleyebilmek adına yüksek barajların tasarımı da bir zaruret haline gelmiştir. Yüksek düşü nedeniyle baraj membasındaki potansiyel enerjinin dolusavak mansabında kinetik enerjiye dönüşmesi sebebiyle baraj mansabında oluşacak tahribat, araştırmacıların ilgisini çekmiş ve dolusavak üzerindeki akım enerjisini sönümlemeye yönelik fikirler ortaya çıkmıştır. Basamaklı dolusavaklar, üzerindeki basamaklar sayesinde akım içerisine hava katarak su jetinin bölünmesine ve daha yumuşak bir halde baraj mansabına bırakılmasına vesile olmaktadır. Çok uzun yıllardan beridir kullanılan bu doğal havalandırma yönteminin geliştirilmesi ile mansap havuzunda inşa edilen enerji kırıcı yapıların maliyeti azalmaktadır (Chanson, 1998).

Yaklaşık 3000 yıllık bir tarihe sahip olan basamaklı dolusavakların ilk örneğinin Yunanistan'daki Akarnania Baraj1 olduğu tahmin edilmektedir (Chanson, 1998). Basamaklı dolusavaklar, inşa kolaylığı açısından, günümüzde özellikle silindirle sıkıştırılmış beton (SSB) barajlarda (RCC-Roller Compact Concrete) ve dolgu barajlarda taşkın dolusavağ 1 olarak kullanılmaktadır. Genellikle, birim debisi $q=10-15 \mathrm{~m}^{3} \cdot \mathrm{s}^{-1} \cdot \mathrm{m}^{-1}$ ye kadar olan dolusavaklarda kullanılmasının yanı sıra birim debinin $30 \mathrm{~m}^{3} \cdot \mathrm{s}^{-1} \cdot \mathrm{m}^{-1}$ ye kadar arttırılabileceği de savunulmuştur (Boes, 2012). SSB barajlar, klasik beton ile inşa edildiğinden bu barajların mansabına basamaklı dolusavakların inşa edilmesi oldukça ekonomik ve pratiktir (Frizell \& Mefford, 1991). Ayrıca, basamaklı savaklar, akım içerisinde çözünmüş hava miktarının artmasiyla hem akarsu ekolojisine hem de kavitasyon riskine karşı olumlu bir etki sağlamaktadır. Bu sebeple basamaklı dolusavaklar, arıtma tesislerinde su içerisindeki oksijen miktarını arttırmak için de kullanılabilmektedir (Chanson, 1998).

Ülkemizde, Aydın İlindeki Çine Çayı üzerine kurulan Adnan Menderes Barajı; sulama, enerji ve taşkın koruma amaçlarıyla 2010 yılında hizmete başlamıştır. SSB barajlar kategorisinde yer alan bu baraj, membada biriken taşkın sularını basamaklı dolusavaklar yardımıyla baraj mansabına aktarmaktadır (URL1). İzmir'de, İlyas Çayı üzerinde 2011 yılında inşası tamamlanan Çaltıkoru Barajı da SSB tipi bir baraj olup gövdesi üzerine yerleştirilen basamaklı dolusavak ile su tahliyesi yapmaktadır (URL-2).

Basamaklı dolusavaklarda akım; içerisine hava girişinin olduğu ve kinetik enerjinin sönümlendiği şiddetli bir türbülans akımı olarak özetlenebilir (Özbek, 2009). Akımın basamaklara çarpması sonucu hızı azalacağından kinetik enerjisi, dolayısı ile momentumu azalacaktır. Bu sebepten, klasik şütlerdeki akım ile kıyaslandığında, basamaklı dolusavakların enerji sönümleme oranları çok daha yüksektir (Rice \& Kadavy, 1996).

Nap rejiminde akım, her bir basamağa çarparak içerisine hava girmesiyle enerjisi sönümlenmektedir. Ayrıca basamakların uzun olması durumunda, basamak üzerinde oluşan hidrolik sıçramanın topuğunda da akımın enerjisi sönümlenebilmektedir. Sıçramalı akım durumunda ise debi arttıkça akım, basamakları makro pürüzlülük olarak algılayıp basamak uçlarında dolusavak tabanına paralel bir izafi taban oluşturmaktadır. Dolayısı ile nap akımı için kıstas, basamak yüksekliği; sıçramalı akım durumunda ise esas kriter düşü yüksekliğidir (Berkün, 2007; Felder vd., 2012).
Basamaklı dolusavaklarda düşük debi değerlerinde nap akımı, yüksek debi değerlerinde ise sıçramalı akım rejimi oluşmaktadır. İlk kez Ohtsu \& Yasuda (1991) tarafından bu iki akım rejimi arasında bir geçiş rejimi olduğundan bahsedilmiştir. Nap akımı rejiminde, debi arttıkça akım içerisinde çözünen hava miktarı arttığından, belli bir değer sonunda sıçramalı akım rejimine geçiş olmaktadır. Sıçramalı akım rejiminde debi artması durumunda ise akımın her bir basamak üzerinde bulunma süresi azaldığından akım içerisinde çözünen hava miktarında da azalma olmaktadır (Berkün, 2007). Geçiş akım rejimi, nap akımı özelliğini kaybetmiş ancak sıçramalı akım özelliğini tam olarak kazanmamış akım tipidir. Çok fazla titreşim oluşması sebebiyle geçiş rejimi, tasarımcılar tarafından istenmeyen bir durumdur (Chanson, 1996).

Basamaklı dolusavaklarda akım rejimleri arasındaki geçiş sınırı için bazı araştırmacılar (Boes \& Hager, 2003; Chanson, 2001) birtakım kriterler belirlemişlerdir. Chanson (2001), nap akım rejimi ile geçiş akım rejimi arasındaki sınırı Eşitlik (1), geçiş akım rejimi ile sıçramalı akım rejimi arasındaki sınırı Eşitlik (2) ile tanımlamıştır. Boes \& Hager (2003) ise geçiş akım rejimi ile sıçramalı akım rejimi arasındaki sınır için Eşitlik (3)’ü önermişlerdir.

$$
\begin{aligned}
& \frac{y_{c}}{h}=0,89-0,40\left(\frac{h}{l}\right) \\
& \frac{y_{c}}{h}=1,20-0,325\left(\frac{h}{l}\right) \\
& \frac{y_{c}}{h}=0,91-0,14 \tan (\alpha)
\end{aligned}
$$

burada, $y_{c}=$ kritik akım derinliği $(\mathrm{m}), \alpha=$ şüt açısı, $h=$ basamak yüksekliği (m) ve $l=$ basamak uzunluğudur (m).

Yukarıda bahsedildiği üzere, basamaklı dolusavakların pratik ve ekonomik olması geçmişten günümüze birçok tasarımcının ve araştırmacının ilgisini çekmiştir. Basamaklı dolusavaklar ile alakalı ilk çalışmalarda; genellikle tasarım kriterleri, temel eşitliklerin geliştirilmesi ve uygulama alanlarında kullanılabilmesi için kılavuzlar oluşturulmuştur (Boes \& Hager, 2003; Chanson, 1993, 2001; Essery, I. T. S., \& Horner, 1971; Sorensen, 1985). Araştırmacıların bir kısmı, kutu gabyonlar kullanarak basamaklı dolusavaklar üzerindeki akım karakteristiklerini incelemişlerdir (Peyras vd., 1992; Wuthrich \& Chanson, 2015; Zuhaira vd., 2020). Bir kısım araştırmacılar da basamaklı dolusavakların mansabında oluşan oyulmayı incelemişlerdir (Aminpour \& Farhoudi, 2017; Eghlidi vd., 2020; Tuna \& Emiroglu, 2013). Bilgisayar teknolojisinin gelişmesi ile hesaplamalı akışkanlar dinamiği (HAD) (Computational Fluid Dynamics-CFD) yöntemi, araştırmacıların ilgisini çekmiş ve basamaklı dolusavaklar üzerinde yapılan sayısal çalışmaların sayısı gün geçtikçe artmıştır. Bu araştırmalarda genellikle farklı basamak geometrileri, basamak uçlarına yerleştirilen farklı geometrideki eşikler ya da farklı kanal açısına sahip şütler kullanılarak enerji sönümleme oranları incelenmiştir (Arjenaki vd., 2020; Ashoor \& Riazi, 2019; Azman vd., 2020; Ghaderi vd., 2020; Hekmatzadeh vd., 2018; Shicheng Li vd., 2020; Shuai Li vd., 2018; Mohammad vd., 2016; Reeve vd., 2019; Shahheydari vd., 2015; Stojnic vd., 2021; Tabbara vd., 2005; Thappeta vd., 2020; Zabaleta vd., 2020). 
$\mathrm{Bu}$ çalışmada, literatürde olmayan, ters basamak geometrisindeki eşikler kullanılarak tasarlanan basamaklı savakların enerji sönümleme oranı Flow3D ${ }^{\circledR}$ yazılımı ile sayısal olarak incelenmiştir. Yazılımın doğrulanmasında Mero \& Mitchell (2017) tarafından yürütülen klasik basamaklı savakların deneysel sonuçları kullanılmıştır.

\section{Materyal ve Metot}

\subsection{Sayisal Model}

Sayısal çalışmadaki ilk aşama katı cisim tasarımı olduğundan bahse konu modelin oluşturulması için Solidworks yazılımı kullanılmış ve oluşturulan katı cisimler .stl uzantılı olarak Flow3D ${ }^{\circledR}$ yazılımına aktarılmıştır. Flow3D ${ }^{\circledR}$, modellemeler için sonlu hacimler yöntemini (Volume of FluidVOF) ve FAVOR (Fractional Area-Volume Obstacle Representation) yöntemini kullanmaktadır. VOF metodu, serbest yüzeydeki akışkan davranışını göstermek için kullanılır. Sıvı içeren elemanlarda basınç, sıcaklık ve hız gibi akış değişkenlerinin her biri için sayısal değerler tutulur. Bu değerler, her bir öğedeki ortalama değer hacmini temsil eder. FAVOR metodu ise katı yüzeyler ve geometrik sınırlar gibi hacimleri analiz etmek için kullanılır. Problem geometrisi, her bir elemanın alan fraksiyonu ve hacim fraksiyonu hesaplanarak tanımlanır (Flow Science Incorporated, 2016).

Flow3D ${ }^{\circledR}$, Navier-Stokes ve genel kütle denklemlerini kullanarak iki ya da üç boyutta çözümler yapabilmektedir. Genel olarak kullanılan denklemler aşağıda verilmiştir (Flow Science Incorporated, 2016).

$$
\begin{aligned}
& \frac{\partial u}{\partial t}+u \frac{\partial u}{\partial x}+v \frac{\partial u}{\partial y}+w \frac{\partial u}{\partial z}=-\frac{1}{\rho} \frac{\partial p}{\partial x}+X+v\left(\frac{\partial^{2} u}{\partial x^{2}}+\frac{\partial^{2} u}{\partial y^{2}}+\frac{\partial^{2} u}{\partial z^{2}}\right) \\
& \frac{\partial v}{\partial t}+u \frac{\partial v}{\partial x}+v \frac{\partial v}{\partial y}+w \frac{\partial v}{\partial z}=-\frac{1}{\rho} \frac{\partial p}{\partial y}+Y+v\left(\frac{\partial^{2} v}{\partial x^{2}}+\frac{\partial^{2} v}{\partial y^{2}}+\frac{\partial^{2} v}{\partial z^{2}}\right) \\
& \frac{\partial w}{\partial t}+u \frac{\partial w}{\partial x}+v \frac{\partial w}{\partial y}+w \frac{\partial w}{\partial z}=-\frac{1}{\rho} \frac{\partial p}{\partial z}+Z+v\left(\frac{\partial^{2} w}{\partial x^{2}}+\frac{\partial^{2} w}{\partial y^{2}}+\frac{\partial^{2} w}{\partial z^{2}}\right)
\end{aligned}
$$

$x$, $y$ ve $z$ kartezyen koordinatlarına göre Navier-Stokes denklemlerinin açılımları verilmiştir. Burada $\rho$, akışkanın özgül kütlesi, $p$, basınç ve $v$, kinematik viskozitedir. Denklemlerde belirtilen $X, Y$ ve $Z$, ilgili eksendeki kütlesel ivmeyi göstermektedir. Düşey eksende ( $Z$ ekseni) yerçekimi ivmesi etki ettiğinden $Z=9,81 \mathrm{~m} . \mathrm{s}^{-2}$ olarak alınırken diğer eksenlerde herhangi bir kütlesel ivme tanımlanmamıştır.

\subsection{Geometrik Model}

Sayısal çalışmanın doğrulanması için kullanılan deneysel çalışmadaki (Mero \& Mitchell, 2017) modelin yüksekliği 0,25 m ve genişliği 0,296 m'dir. Toplamda beş basamaktan oluşan savağın her bir basamağının yüksekliği $0,05 \mathrm{~m}$ ve genişliği 0,10 m olmak üzere kanal açısı 26,6 ' dir (Şekil 1).

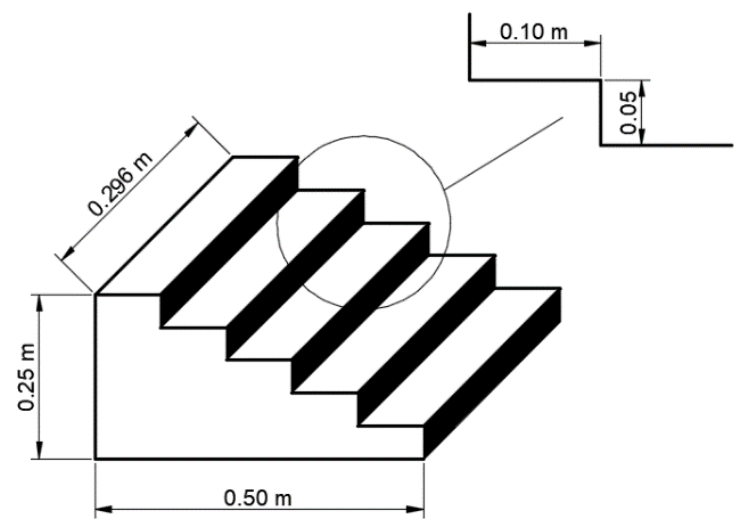

Şekil 1. Mero \& Mitchell (2017) tarafindan tasarlanan model geometrisi

Yürütülen sayısal çalışmada, ters basamak geometrisindeki eşikler, farklı sıradaki basamaklara yerleştirilmiştir. Elde edilen üç farklı modelin, altı farklı debi altında enerji sönümleme oranları incelenmiştir. Tasarlanan ters basamaklı savaklarda kullanılan eşiklerin geometrisi Şekil 2(a)'da gösterilmiştir. Model 1'de, her bir basamak ucuna, toplamda $2,50 \mathrm{~cm}$ yüksekliğinde ve $1,25 \mathrm{~cm}$ basamak uzunluğunda eşikler yerleştirilmiştir. Model 2'de, Model 1'de kullanılan eşikler, birinci ve üçüncü basamaklara yerleştirilmiştir. Model 3 'te ise eşikler, ikinci ve dördüncü basamağa yerleştirilerek analizler yürütülmüştür (Şekil 2).

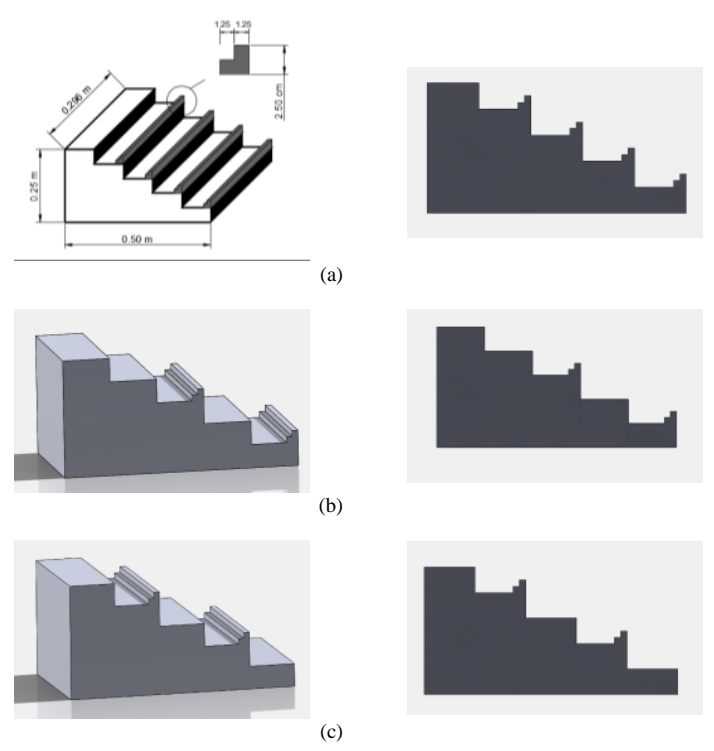

Şekil 2. Sayısal çalışma için tasarlanan modeller:

a) Model 1; b) Model 2 ve c) Model 3

Çalışma kapsamında, literatürde belirlenen (Boes \& Hager, 2003; Chanson, 2001) kriterlere göre, üç farklı akım rejiminde de enerji sönümleme oranları incelenmiştir. Akım değerleri çok daha erken zamanda stabil hale gelmesine rağmen bütün modeller için analizler 10 saniye boyunca devam ettirilmiştir. Çalışmada (Mero \& Mitchell, 2017) kullanılan hidrolik karakteristikler Tablo 1'de gösterilmiştir. 
Tablo 1. Hidrolik karakteristikler (Mero \& Mitchell, 2017)

\begin{tabular}{|c|c|c|c|c|c|}
\hline$\underset{\left(\mathbf{m}^{3} \cdot \mathbf{s}^{-1}\right)}{Q}$ & $\begin{array}{c}y_{c}=\left(q^{2} / g\right)^{1 / 3} \\
(\mathrm{~m})\end{array}$ & $\begin{array}{c}\text { Basamak } \\
\text { yüksekliği }(h) \\
(\mathbf{m})\end{array}$ & $\begin{array}{c}\text { Basamak } \\
\text { uzunluğu }(l) \\
(\mathbf{m})\end{array}$ & $y_{c} / h$ & Akım rejimi \\
\hline 0,0121 & 0,055 & 0,05 & 0,10 & 1,109 & Sıçramalı akım \\
\hline 0,00831 & 0,043 & 0,05 & 0,10 & 0,863 & Sıçramalı akım \\
\hline 0,00684 & 0,038 & 0,05 & 0,10 & 0,758 & Geçiş \\
\hline 0,00563 & 0,033 & 0,05 & 0,10 & 0,666 & Nap akımı \\
\hline 0,00464 & 0,029 & 0,05 & 0,10 & 0,585 & Nap akımı \\
\hline 0,00363 & 0,025 & 0,05 & 0,10 & 0,497 & Nap akımı \\
\hline
\end{tabular}

\subsection{Enerji Sönümleme Oranı}

Deneysel çalışmada (Mero \& Mitchell, 2017), savak üzerindeki kritik akım derinliği kullanılarak toplam enerji yüksekliği hesaplanmıştır. Kanal, dikdörtgen olduğundan kritik akım derinliği için Eşitlik (7) kullanılmıştır.

$$
q=\frac{Q}{B} \quad \text { ve } \quad y_{c}=\sqrt[3]{\frac{q^{2}}{g}}
$$

burada, $y_{c}$, savak üzerindeki kritik akım derinliği (m); $Q$, akım debisi $\left(\mathrm{m}^{3} \cdot \mathrm{s}^{-1}\right) ; q$, birim debi $\left(\mathrm{m}^{3} \cdot \mathrm{s}^{-1} \cdot \mathrm{m}^{-1}\right) ; B$, kanal genişliği $(\mathrm{m})$ ve $g$, yerçekimi ivmesidir $\left(\mathrm{m} . \mathrm{s}^{-2}\right)$. Eşitlik (8-9) kullanılarak, Şekil 3 'te gösterilen (0) ve (1) noktalarındaki enerjiler hesaplanmıştır. Daha sonra Eşitlik (10) kullanılarak iki nokta arasındaki enerji farkı hesaplanmıştır (Mero \& Mitchell, 2017).

$$
\begin{aligned}
& E_{0}=H_{\text {savak }}+y_{c}+\frac{V_{c}{ }^{2}}{2 g}=H_{\text {savak }}+1,50 y_{c} \\
& E_{1}=y_{1}+\frac{V_{1}{ }^{2}}{2 g} \\
& E_{L}=E_{0}-E_{1}
\end{aligned}
$$

burada, $E_{0}$, savak üzerindeki enerjiyi (m); $H_{\text {savak }}$, savak yüksekliğini $(\mathrm{m}) ; y_{1}$, mansap su derinliğini $(\mathrm{m}) ; V_{c}$, kritik hızı $\left(\mathrm{m} . \mathrm{s}^{-1}\right) ; V_{1}$, mansaptaki ortalama hızı $\left(\mathrm{m} . \mathrm{s}^{-1}\right) ; E_{1}$, mansaptaki enerjiyi $(\mathrm{m})$ ve $E_{L}$, memba ve mansap enerjilerinin farkını (m) ifade etmektedir.

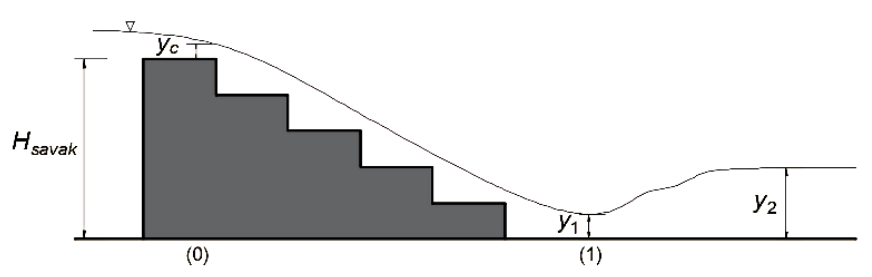

Şekil 3. Savak boykesiti

\section{4. Çözüm Ăğı ve Sınır Şartları}

Sayısal çalışmalarda dikkat edilmesi gereken en önemli unsur, çözüm ağı yapısıdır. Seçilen çözüm ağındaki hücre boyutları ne kadar küçülürse katı cisim o kadar gerçeği yansıttığından elde edilecek sonuçlar da o kadar doğruya yakınsamaktadır. Ancak, çözüm ağındaki hücre boyutları küçüldükçe iterasyon sayısı arttığından çözüm süresi de artmaktadır. Dolayısı ile hücre sayısı arttıkça çok daha kapasiteli bilgisayarların kullanımı bir gereksinim haline gelmektedir. $\mathrm{Bu}$ sebeple, hücre boyutları optimize edilerek en uygun boyutlar seçilmelidir. Kullanılan modellerde bütün hücreleri aynı derece küçültmektense sadece detaylar üzerinde küçültme yapmak hem toplam hücre sayısını azaltmakta hem de simülasyon süresini kısaltmaktadır. Dolayısı ile, kullanılan katı cisimlerin net bir şekilde algılanabilmesi için hem basamak köşe noktalarında hem de eşik geometrisi üzerinde ekstra çözüm yüzeyleri oluşturularak çözüm ağı tasarlanmıştır (Şekil 4).

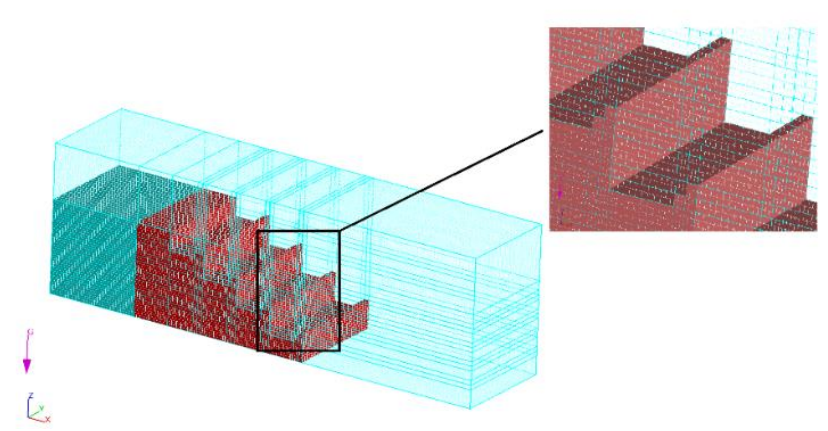

Şekil 4. Çözüm ă̆l yapısı

Model 1 için yürütülen deneme analizlerinde ilk etapta 141360 adet çözüm hücresi seçilerek analizler yürütülmüştür. Daha sonra boyutlar küçültülerek toplam hücre sayısı 672672'ye kadar arttırılmıştır. Tablo 2'de de görüldügüü üzere, belli bir değerden sonra hücre sayısının artması sonucu çok fazla etkilemediğinden en büyük hücre boyutu $1,20 \mathrm{~cm}$ ve en küçük hücre boyutu $0,42 \mathrm{~cm}$ olarak belirlenerek toplamda 488670 adet çözüm hücresinin bu çalışma için yeterli olduğu kanaatine varılmıştır (Şekil 5). 


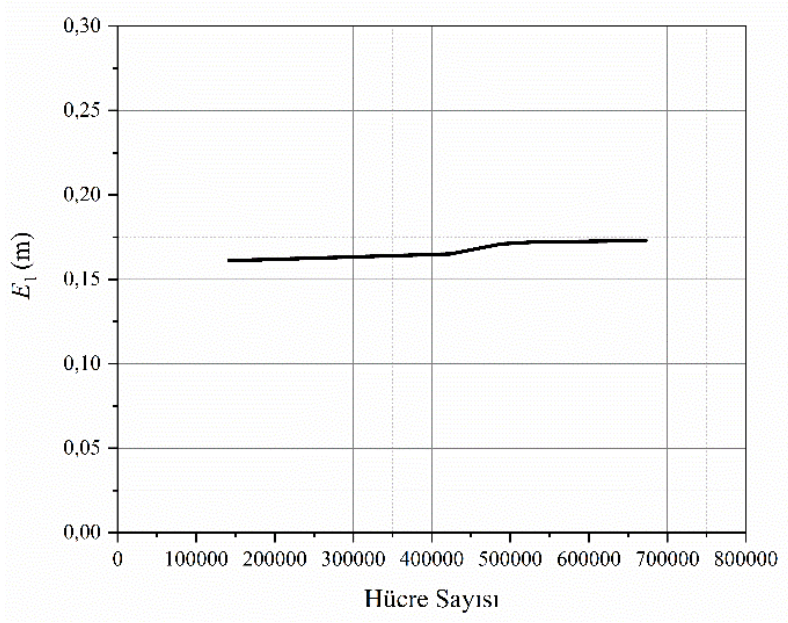

Şekil 5. Hücre sayısının mansaptaki enerji yüksekliğine etkisi (Model 1, $Q=0.0121 \mathrm{~m}^{3} \cdot \mathrm{s}^{-1}$ )

Tablo 2. Toplam hücre sayısının enerji değisşimine etkisi (Model 1, $Q=0.0121 \mathrm{~m}^{3} \cdot \mathrm{s}^{-1}$ )

\section{Çözüm ağı hücre boyutları (Maksimum-Minimum)} (cm)

\section{Toplam hücre sayısı}

$E_{1}$

(Savak mansabındaki enerji)

(m)

\begin{tabular}{lll}
\hline \hline $1,50-0,60$ & 141360 & 0,161 \\
$1,40-0,42$ & 423345 & 0,165 \\
$1,20-0,42$ & 488670 & 0,171 \\
$1,10-0,41$ & 526240 & 0,172 \\
$1,10-0,30$ & 672672 & 0,173 \\
\hline
\end{tabular}

Deney düzeneğindeki fiziksel şartların simülasyona aktarılabilmesi için sınır şartlarının doğru belirlenmesi gerekmektedir. Savak üzerinden birim zamanda sabit bir akımın geçebilmesi için $x_{\min }$ yüzeyine debi $(Q)$ ve savak yüksekliği kadar su tanımlanmıştır. Tanımlanan debiye göre akım yüksekliği yazılım sayesinde otomatik olarak hesaplanmaktadır. Akımın, mansap kısmına birikmemesi için $x_{\max }$ yüzeyine çıkış $(O)$, kanalın sağ ve sol yüzeyleri $\left(y_{\min }\right.$ ve $\left.y_{\max }\right)$ ile kanal tabanına duvar $(W)$ sınır şartı tanımlanmıştır (Şekil 6).

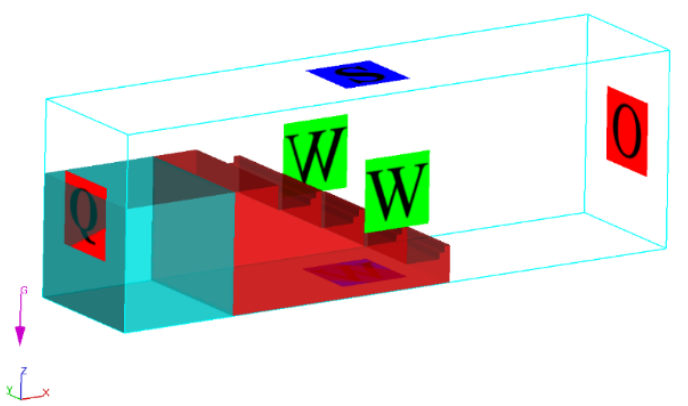

Şekil 6. Sinır şartları

\subsection{Sayısal Sonuçların Doğrulanması}

Sayısal sonuçları deneysel sonuçlarla (Mero \& Mitchell, 2017) doğrulamak için RNG k-e ve Standart k-e türbülans modelleri kullanılmıştır. Sonuçlar kıyaslandığında, RNG k-e türbülans modelinde hata oranlarının \%20’leri aştığı görülmektedir (Şekil 7). Bu değerlerdeki sapmaların, sayısal iterasyonlardaki hatalardan kaynaklandığ 1 düşünülmektedir. Debi değerleri küçük olduğundan kesit boyunca sabit bir değer okumak oldukça zordur. Standart k-e modelinde ise kısmen sapmalar gözlenmekte olup kabul edilebilir düzeyde olduğu düşünülmektedir. $\mathrm{Bu}$ nedenle, standart k-e türbülans modelinin çalışma için daha uygun olduğu kanaatine varılmıştır. 


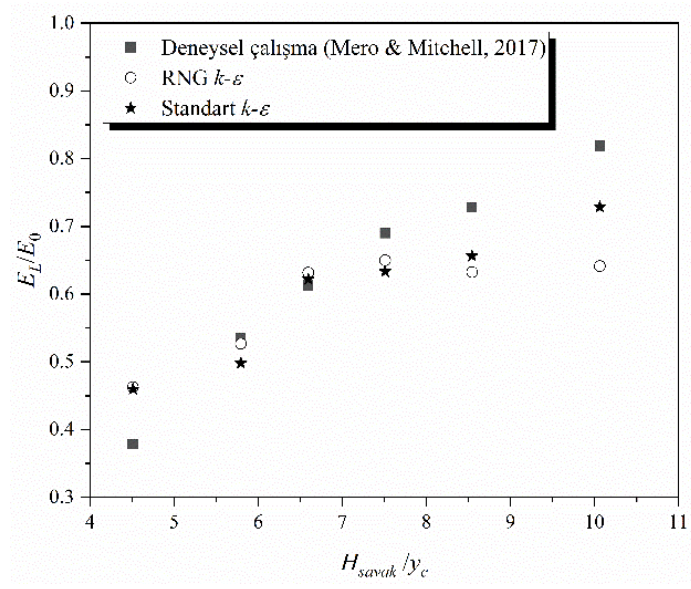

Şekil 7. Sayısal çalışmanın doğrulanması

\section{Araştırma Sonuçları ve Tartışma}

Dolusavaklar, membadaki akımı mansaba güvenle aktarmak ile görevli elemanlardır. Bu yapıların membasındaki akımın sahip olduğu potansiyel enerji, mansapta kinetik enerjiye dönüştüğünden mansaptaki akım hızının daha yüksek olduğu bilinmektedir. $\mathrm{Bu}$ sebeple tasarımcılar, enerji kırıcı havuzun maliyetlerini düşürebilmek için basamaklı savakları kullanmışlardır. Bu çalışma kapsamında oluşturulan üç farklı model ile basamaklı savakların mansap hızlarının biraz daha düşürülmesi planlanmıştır. Şekil 8 ' de, $Q=0.0121 \mathrm{~m}^{3} \cdot \mathrm{s}^{-1}$ için, kanal en kesiti üçe bölünerek orta kısımdan okunan akım hız dağılımları gösterilmiştir. Model 1'in hız dağılımı, klasik basamaklı savakların hız dağılımının altında kalırken, Model 2 ve Model 3 için aynı durum söz konusu değildir. Model 1'de her bir basamak ucundaki eşiğe çarpan akım, hızını kaybederken Model 2 ve Model 3'te basamak ucundaki eşiğe çarpan akım sıçrayarak bir sonraki basamağa çarpmadan ilerlemektedir. Böylece, akım hızlanarak ilerlemektedir. Model 2 ve Model 3'ü kendi içlerinde kıyaslarsak, Model 2'nin son basamağında eşik olduğundan akım, enerjisinin bir kısmını bu basamakta bırakmaktadır. Model 3'te ise son basamak üzerinde eşik olmadığından bir önceki basamak ucundan sıçrayan akım direkt mansap havuzuna çarpmaktadır. Dolayısı ile en yüksek hız Model 3'ün mansabında, en düşük hız ise Model 1'in mansabında gözlenmiştir.

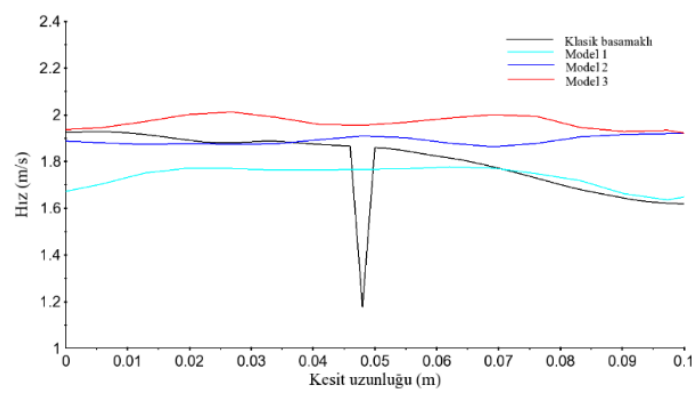

Şekil 8. $Q=0.0121 \mathrm{~m}^{3} . \mathrm{s}^{-1}$ için kullanılan modellerin kanal enkesitindeki hız dă̆ılımı

Türbülans sönümleme değeri, akım içerisindeki çalkantıların ne denli sönümlendiğini gösteren bir kriterdir. Türbülans, hız ile doğru orantılı olduğundan savak üzerindeki akımın türbülansı ne kadar sönümleniyorsa savak mansabındaki akım hızı da o kadar azalmaktadır. Dolayısı ile savak mansabında kalan enerji azalmaktadır. Sıçramalı akım durumunda, Model 1 üzerindeki akımda türbülans sönümleme değerlerinin klasik basamaklı savağa kıyasla biraz daha erken başladığı görülmektedir (Şekil 9). Klasik basamaklı, Model 1 ve Model 2'nin türbülans sönümlenmeleri birbirine yakın görünmektedir. Ancak Model 3, üzerindeki renk dağılımından da görüldüğü üzere, türbülans sönümlemede diğer modellerin gerisinde kalmaktadır. Ayrıca, eşikli savaklarda oluşan dalgalı su yüzü profili klasik basamaklı savaklarda gözlenmemektedir.

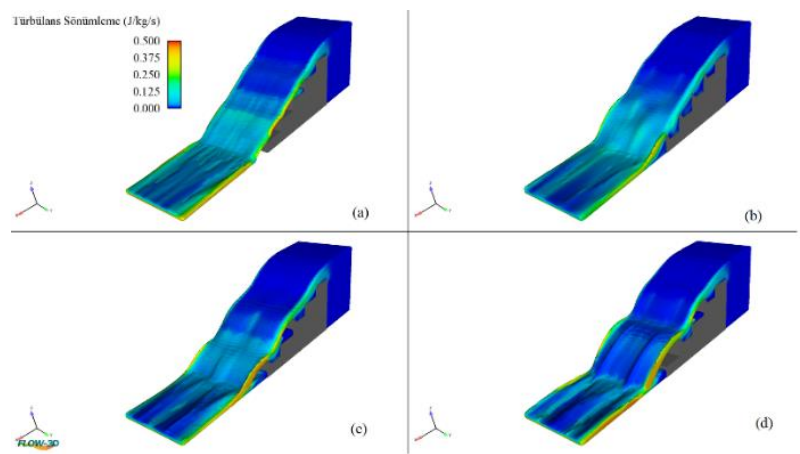

Şekil 9. $Q=0.0121 \mathrm{~m}^{3} . \mathrm{s}^{-1}$ için üç boyutlu türbülans sönümleme dağllımlart:

a) klasik basamaklı savak; b) Model 1; c) Model 2; d) Model 3

Şekil 10'da modellerin toplam enerjileri üç boyutlu olarak gösterilmiştir. Model 1'de, basamak ucundaki eşiklere çarpan akımın hızı azaldığından enerjisi diğer modellere kıyasla daha fazla sönümlenmiştir. Klasik basamaklı savak üzerindeki akım hızı yüksek olduğundan kanal üzerindeki akım yüksekliği daha düşüktür. Model 1'de ise akım hızı düştüğünden kanal üzerindeki akım yüksekliği daha fazla olmaktadır. Bu durum enerji sönümleme açısından olumlu iken yan duvar yüksekliği açısından olumsuz bir durumdur. Model 2 ve 3 'te basamak uçlarına eklenen eşikler, bir basamak boşluk bırakılarak tasarlandığından eşiklere çarpan akım sıçrayarak bir sonraki basamağa çarpmadan ilerlemektedir. Özellikle Model 3 'te son eşiğe çarpan akım bir sonraki basamağa çarpmadan mansap havuzuna düştüğünden ve akım hızı gerektiği kadar azalmadığından mansaptaki enerji miktarında da beklenen azalma gözlenmemiştir (Şekil 10).

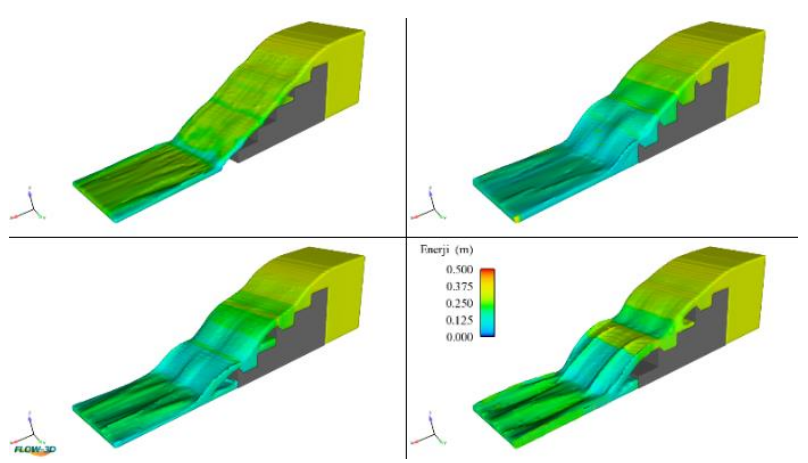

Şekil 10. Farklı modeller üzerinden savaklanan akımın enerji dağılımı: a) klasik basamaklı savak; b) Model 1; c) Model 2; d) Model 3 
Bu çalışma kapsamında kullanılan debiler sayesinde nap, geçiş ve sıçramalı akım rejimlerini görmek mümkün olmaktadır. Şekil 11'de, çalışma kapsamındaki basamaklı savakların enerji sönümleme oranlarının boyutsuz kritik akım derinliğine $\left(y_{c} / h\right)$ göre değişimi incelenmiştir. Akım rejim sınırları, literatürde verilen eşitlikler yardımıyla elde edilmiştir (Boes \& Hager, 2003; Chanson, 2001). Buna göre, boyutsuz kritik akım derinliğinin artmasıyla, yani debinin artmasıyla, sönümleme oranlarında genellikle azalma olduğu görülmektedir. Sıçramalı akım durumunda, Model 1 ile klasik basamaklı savak arasındaki sönümleme farkı maksimum \%18 civarlarında iken nap akım rejimine doğru sönümleme farkı da azalmaktadır. Sıçramalı akım rejiminde basamak ucundaki eşiklere çarpan akım, enerjisinin bir kısmını kaybetmektedir. Dolusavaklarda taşkın debileri ya da rezervuarda biriken ihtiyaç fazlası suların sıçramalı akım şartlarını taşıdığı düşünülürse, her bir basamak ucuna eklenen ters basamaklı eşiklerin akım enerjisini sönümlemede olumlu katkı sağlayacağı düşünülmektedir. Model 2 ve 3'ün sıçramalı akım şartlarında akım enerjisini sönümlemede başarılı olmadığı görülmektedir.

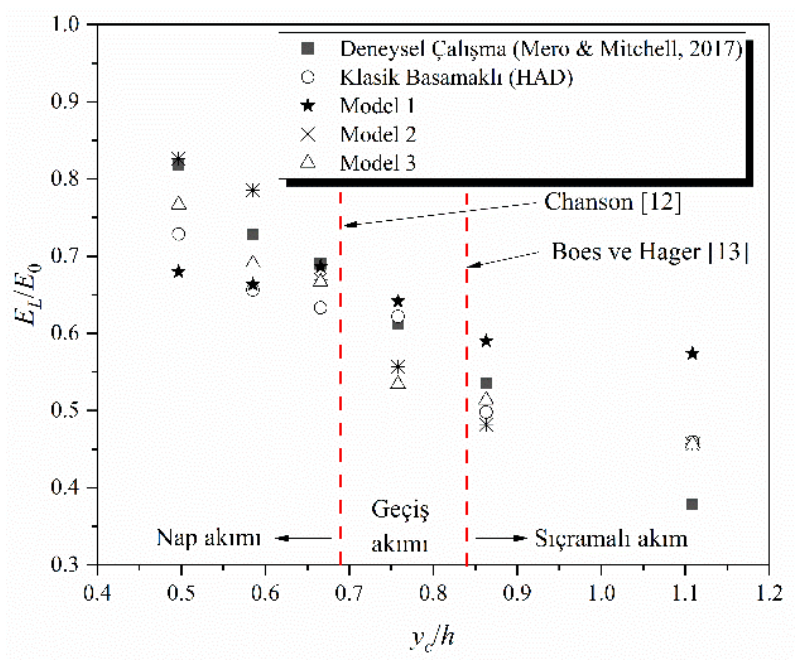

Şekil 11. Kullanılan modellerin enerji sönümleme oranlarının boyutsuz kritik akım derinliğine oranı

\section{Sonuç}

Çalışma kapsamında, ters basamaklı eşikler kullanılarak oluşturulan basamaklı savakların enerji sönümleme oranları Flow3D ${ }^{\circledR}$ yazılımı ile sayısal olarak incelenmiştir. Sayısal modelin doğrulanması için Mero \& Mitchell (2017) tarafindan tasarlanan klasik basamaklı dolusavak modeli kullanılmıştır. Altı farklı debi altında üç farklı model kullanılarak toplamda 18 adet analiz yürütülmüştür. Elde edilen sonuçlara göre, birer basamak boşluk bırakılarak yerleştirilen eşikli modellerin, sıçramalı akım şartlarında, enerji sönümlemede başarılı olmadığ ${ }_{1}$, her bir basamak ucuna yerleştirilen ters basamaklı eşiklerin klasik basamaklı savaklara oranla \%18'e kadar daha fazla enerji sönümleyebildiği, debinin azalmasına bağlı olarak sönümleme oranları arasındaki farkın düştüğü, debi artışıyla birlikte enerji sönümleme oranının genellikle azaldığı ve bu durumun literatürdeki çalışmalarla uyumlu olduğu kanaatine varılmıştır.

\section{Teșekkür}

$\mathrm{Bu}$ çalışmada kullanılan Flow3D ${ }^{\circledR}$ (v11.2) ve Solidworks yazılımları için Fırat Üniversitesi’ne teşekkür ederiz.

\section{Kaynakça}

Aminpour, Y., \& Farhoudi, J. (2017). Similarity of Local Scour Profiles Downstream of Stepped Spillways. International Journal of Civil Engineering, 15(5), 763-774. https://doi.org/10.1007/s40999-017-0168-9

Arjenaki, M. O., Hamed, ·, \& Sanayei, R. Z. (2020). Numerical investigation of energy dissipation rate in stepped spillways with lateral slopes using experimental model development approach. Modeling Earth Systems and Environment, 6, 605-616. https://doi.org/10.1007/s40808020-00714-z

Ashoor, A., \& Riazi, A. (2019). Stepped Spillways and Energy Dissipation: A Non-Uniform Step Length Approach. Applied Sciences, $\quad 9(23), \quad 5071$. https://doi.org/10.3390/app9235071

Azman, A., Ng, F. C., Zawawi, M. H., Abas, A., Rozainy M. A. Z, M. R., Abustan, I., Adlan, M. N., \& Tam, W. L. (2020). Effect of Barrier Height on the Design of Stepped Spillway Using Smoothed Particle Hydrodynamics and Particle Image Velocimetry. KSCE Journal of Civil Engineering, 24(2), 451-470. https://doi.org/10.1007/s12205-020-1605-X

Berkün, M. (2007). Su Yapıları. Birsen Yayınevi.

Boes, R. M. (2012). Guidelines on the design and hydraulic characteristics of stepped spillways. Proceedings of the 24th ICOLD Congress on Large Dams, 203-220.

Boes, R. M., \& Hager, W. H. (2003). Hydraulic Design of Stepped Spillways. Journal of Hydraulic Engineering, 129(9), 671-679. https://doi.org/10.1061/(asce)07339429(2003)129:9(671)

Chanson. (1993). Stepped spillway flows and air entrainment. Canadian Journal of Civil Engineering, 20(3), 422-435. https://doi.org/10.1139/193-057

Chanson. (1996). Prediction of the transition nappe/skimming flow on a stepped channel. Journal of Hydraulic Research, 34(3), 421-429. https://doi.org/10.1080/00221689609498490

Chanson. (1998). Review of studies on stepped channel flows. Workshop on Flow Characteristics around Hydraulic Structures and River Environment, 25.

Chanson. (2001). Hydraulic Design of Stepped Spillways and Downstream Energy Dissipators. Dam Engineering.

Eghlidi, E., Barani, G. A., \& Qaderi, K. (2020). Laboratory Investigation of Stilling Basin Slope Effect on Bed Scour at Downstream of Stepped Spillway: Physical Modeling of Javeh RCC Dam. Water Resources Management, 34(1), 87-100. https://doi.org/10.1007/s11269-019-02395-5

Essery, I. T. S., \& Horner, M. W. (1971). The Hydraulic Design of Stepped Spillways. Construction Industry Research and Information Association.

Felder, S., Fromm, C., \& Chanson, H. (2012). THE UNIVERSITY OF QUEENSLAND REPORT CH86/12 AIR ENTRAINMENT AND ENERGY DISSIPATION ON A $8.9^{\circ}$ SLOPE STEPPED SPILLWAY WITH FLAT AND POOLED STEPS SCHOOL OF CIVIL ENGINEERING.

Flow Science Incorporated. (2016). FLOW-3D Users Manual (11.2). https://www.flow3d.com/

Frizell, K. H., \& Mefford, B. W. (1991). Designing Spillways to Prevent Cavitation Damage. Concrete International, 13(5), 58-64.

Ghaderi, A., Abbasi, S., Abraham, J., \& Azamathulla, H. M. 
(2020). Efficiency of Trapezoidal Labyrinth Shaped stepped spillways. Flow Measurement and Instrumentation, 72, 101711. https://doi.org/10.1016/j.flowmeasinst.2020.101711

Hekmatzadeh, A. A., Papari, S., \& Amiri, S. M. (2018). Investigation of Energy Dissipation on Various Configurations of Stepped Spillways Considering Several RANS Turbulence Models. Iranian Journal of Science and Technology - Transactions of Civil Engineering, 42(2), 97109. https://doi.org/10.1007/s40996-017-0085-9

Li, Shicheng, Yang, J., \& Li, Q. (2020). Numerical Modelling of Air-Water Flows over a Stepped Spillway with Chamfers and Cavity Blockages. KSCE Journal of Civil Engineering, 24(1), 99-109. https://doi.org/10.1007/s12205-020-1115-X

Li, Shuai, Zhang, J., \& Xu, W. (2018). Numerical investigation of air-water flow properties over steep flat and pooled stepped spillways. Journal of Hydraulic Research, 56(1), 1-14. https://doi.org/10.1080/00221686.2017.1286393

Mero, S., \& Mitchell, S. (2017). Investigation of energy dissipation and flow regime over various forms of stepped spillways. Water and Environment Journal, 31(1), 127137. https://doi.org/10.1111/wej.12224

Mohammad, M., Tabari, R., \& Tavakoli, S. (2016). Effects of Stepped Spillway Geometry on Flow Pattern and Energy Dissipation. Arab J Sci Eng, 41, 1215-1224. https://doi.org/10.1007/s13369-015-1874-8

Ohtsu, I., \& Yasuda, Y. (1991). Transition from supercritical to subcritical flow at an abrupt drop. Journal of Hydraulic Research, 29(2), 309-328. https://doi.org/10.1080/00221689109498436

Özbek, T. (2009). Açık Kanal Akımlarının Hidroliği ve Hidrolik Yapılar. Teknik Yayınevi.

Peyras, L., Royet, P., \& Degoutte, G. (1992). Flow and Energy Dissipation over Stepped Gabion Weirs. Journal of Hydraulic Engineering, 118(5), 707-717. https://doi.org/10.1061/(asce)0733-9429(1992)118:5(707)

Reeve, D. E., Zuhaira, A. A., \& Karunarathna, H. (2019). Computational investigation of hydraulic performance variation with geometry in gabion stepped spillways. Water Science and Engineering, 12(1), 62-72. https://doi.org/10.1016/j.wse.2019.04.002

Rice, C. E., \& Kadavy, K. C. (1996). Model Study of a Roller Compacted Concrete Stepped Spillway. Journal of Hydraulic Engineering, 122(6), 292-297. https://doi.org/10.1061/(asce)0733-9429(1996)122:6(292)

Shahheydari, H., Nodoshan, J., Barati, R., \& Moghadam, M. A.
(2015). Discharge Coefficient and Energy Dissipation over Stepped Spillway under Skimming Flow Regime. KSCE Journal of Civil Engineering, 19(4), 1174-1182. https://doi.org/10.1007/s12205-013-0749-3

Sorensen, R. M. (1985). Stepped Spillway Hydraulic Model Investigation. Journal of Hydraulic Engineering, 111(12), 1461-1472. https://doi.org/10.1061/(asce)07339429(1985)111:12(1461)

Stojnic, I., Pfister, M., Matos, J., \& Schleiss, A. J. (2021). Effect of 30-Degree Sloping Smooth and Stepped Chute Approach Flow on the Performance of a Classical Stilling Basin. Journal of Hydraulic Engineering, 147(2), 04020097. https://doi.org/10.1061/(asce)hy.19437900.0001840

Tabbara, M., Chatila, J., \& Awwad, R. (2005). Computational simulation of flow over stepped spillways. Computers and Structures, $\quad$ 83(27), 2215-2224. https://doi.org/10.1016/j.compstruc.2005.04.005

Thappeta, S. K., Bhallamudi, S. M., Chandra, V., Fiener, P., \& Baki, A. B. M. (2020). Energy Loss in Steep Open Channels with Step-Pools. Water, 13(1), 72. https://doi.org/10.3390/w13010072

Tuna, M. C., \& Emiroglu, M. E. (2013). Effect of Step Geometry on Local Scour Downstream of Stepped Chutes. Arabian Journal for Science and Engineering, 38(3), 579588. https://doi.org/10.1007/s13369-012-0335-X

Wuthrich, D., \& Chanson, H. (2015). Aeration performances of a gabion stepped weir with and without capping. Environmental Fluid Mechanics, 15(4), 711-730. https://doi.org/10.1007/s10652-014-9377-9

Zabaleta, F., Bombardelli, F. A., \& Toro, J. P. (2020). Towards an understanding of the mechanisms leading to air entrainment in the skimming flow over stepped spillways. Environmental Fluid Mechanics, 20(2), 375-392. https://doi.org/10.1007/s10652-019-09729-2

Zuhaira, A. A., Horrillo-Caraballo, J. M., Karunarathna, H., \& Reeve, D. E. (2020). Investigating skimming flow conditions over stepped spillways using particle image velocimetry. IOP Conference Series: Materials Science and Engineering, 888(1), 012023. https://doi.org/10.1088/1757-899X/888/1/012023

URL-1-Adnan Menderes Barajı - Vikipedi. Retrieved March 6, 2021, https://tr.wikipedia.org/wiki/Adnan_Menderes_Baraj1

URL-2-Çaltıkoru Barajı - Vikipedi. Retrieved March 6, 2021, from https://tr.wikipedia.org/wiki/Çaltıkoru_Baraj1 